\title{
Dormência e dominância apical de diferentes tamanhos de tubérculos de batata
}

\author{
Dormancy and apical dominance of different sizes of potato tubers
}

\author{
Douglas Renato Müller ${ }^{I}$ Dilson Antonio Bisognin ${ }^{\text {II }}$ Glademir Roque Morin ${ }^{\text {III }}$ \\ Francisco Saccol Gnocato ${ }^{\text {III }}$
}

\section{RESUMO}

\begin{abstract}
O tamanho dos tubérculos de batata produzidos em uma mesma cova é um indicativo da idade fisiológica e do período necessário para o rompimento da dormência e da dominância apical, o que é fundamental para o adequado manejo pós-colheita. O objetivo deste trabalho foi avaliar o periodo de dormência e de dominância apical em diferentes tamanhos de tubérculos de três clones de batata, produzidos no outono e submetidos a duas temperaturas de armazenamento. Os tubérculos foram produzidos em campo durante o outono de 2008, sendo colhidas dez covas por clone. Os tubérculos de cada cova foram individualmente identificados e avaliados para massa fresca, comprimento e maior e menor diâmetros, divididos em dois lotes de cinco covas e armazenados, respectivamente, nas temperaturas de 10 e $20^{\circ} \mathrm{C} \pm 2^{\circ} \mathrm{C}$ e $85 \% \pm 5 \%$ de umidade relativa, por 170 dias. $O$ rompimento da dormência e da dominância apical foram anotados quando o tubérculo apresentou, respectivamente, um ou dois brotos. $O$ experimento foi conduzido em um fatorial de três clones (SMINIA00017-6, SMIJ461-1 e Asterix), duas temperaturas de armazenamento $\left(10\right.$ e $\left.20^{\circ} \mathrm{C}\right)$ e três tipos de tubérculo (menor diâmetro inferior a $35 \mathrm{~mm}$, entre 35 e $45 \mathrm{~mm}$ e superior a $45 \mathrm{~mm}$ ), no delineamento experimental inteiramente casualizado. A partir dos resultados, concluiu-se que a idade fisiológica varia com o tamanho dos tubérculos de batata, sendo que tubérculos com diâmetro inferior a $35 \mathrm{~mm}$ apresentam maior período de dormência. Além disso, foi constatado que a temperatura de armazenamento de $20^{\circ} \mathrm{C} e ́$ mais eficaz para o rompimento da dormência do que da dominância apical.
\end{abstract}

Palavras-chave: Solanum tuberosum L., batata-semente, idade fisiológica, armazenamento, brotação.

\begin{abstract}
The size of potato tubers produced in the same hill is an indicator of the physiological age and the time required to break dormancy and apical dominance, which is essential for the proper post-harvest management. The objective of this study was to evaluate the period of dormancy and apical dominance of different tuber sizes of three potato clones produced in the fall and submitted to two storage temperatures. Field produced tubers were harvested from ten hills per clone. The tubers were individually identified and assessed for fresh weight, length and major and minor diameters. One lot of five hills per clone was stored at $10^{\circ} \mathrm{C}$ and other at $20^{\circ} \mathrm{C} \pm 2$ and $85 \pm 5 \%$ relative humidity for 170 days. Breaking of dormancy and apical dominance were recorded when the tuber produced, respectively, one or two sprouts. The experiment was a factorial of three clones (SMINIA00017-6, SMIJ461-1 and Asterix), two storage temperatures $\left(10\right.$ and $20^{\circ} \mathrm{C}$ ) and three types of tubers (smaller diameter less than $35 \mathrm{~mm}$, between 35 and $45 \mathrm{~mm}$ and larger than $45 \mathrm{~mm}$ ) in a completely randomized design. In conclusion, the results showed that physiological age varies with the size of the potato tubers, and tubers with diameter smaller than $35 \mathrm{~mm}$ have longer dormancy than those larger than $35 \mathrm{~mm}$. Moreover, the storage temperature of $20^{\circ} \mathrm{C}$ is more effective to break the dormancy than the apical dominance.
\end{abstract}

Key words: Solanum tuberosum L., potato seeds, physiological age, storage, sprouting.

\section{INTRODUÇÃO}

A atividade metabólica dos tubérculos de batata (Solanum tuberosum L.) está diretamente

'Colégio Agrícola de Frederico Westphalen, Universidade Federal de Santa Maria (UFSM), Frederico Westphalen, RS, Brasil. IIDepartamento de Fitotecnia, UfSM, Av. Roraima, 1000, Bairro Camobi, 97105-900, Santa Maria, RS, Brasil. E-mail: dilsonb@smail.ufsm.br. Autor para correspondência.

${ }^{\mathrm{II}}$ Curso de Agronomia, UFSM, Santa Maria, RS, Brasil. 
associada à idade fisiológica e à maturidade deles, caracterizada pelos estágios de dormência, dominância apical, plena brotação e senescência (BISOGNIN et al., 2008). O final do período de dormência dos tubérculos é caracterizado pelo início da brotação, no qual se observa, em algumas cultivares, a dominância apical, caracterizada pelo crescimento da gema apical e inibição da brotação das gemas laterais. O plantio de tubérculos nesse estágio de brotação resulta em uma lavoura com poucas hastes, não uniforme e de baixo potencial produtivo (HIRANO, 2003; BISOGNIN et al., 2008). A remoção da gema apical ou a atenuação da dominância apical estimula a brotação das gemas laterais (BEUKEMA\& VAN DERZAAG, 1990). Aplena brotação é caracterizada pelo desenvolvimento da maioria dos brotos, até a ramificação dos mais velhos (FONTES \& FINGER, 2000), sendo este considerado o momento ideal para o plantio dos tubérculos (HIRANO, 2003; BISOGNIN et al., 2008).

Apesar de a dormência ser um caráter genético, o balanço hormonal entre promotores e inibidores do crescimento é muito influenciado pela idade fisiológica dos tubérculos, época de cultivo, temperatura de armazenamento, infecção por patógenos, tamanho dos tubérculos e condições ambientais durante o crescimento e desenvolvimento das plantas (ITTERSUM et al., 1993; PÓGI \& BRINHOLI, 1995; FONTES \& FINGER, 2000;BISOGNIN et al., 2008). Estações de cultivo com temperatuas amenas e alta disponibilidade hídrica resultam na produção de tubérculos com maior período de dormência do que aqueles provenientes de estações de cultivo com temperaturas altas e déficit hídrico (FONTES \& FINGER, 1999). Além disso, altas temperaturas durante o crescimento dos tubérculos promove um avanço da idade fisiológica e uma redução do período de dormência (CALDIZ et al., 2001), fazendo com que tubérculos produzidos durante o outono apresentem maior período de dormência do que aqueles produzidos na primavera (BISOGNIN et al., 2008).

Os tubérculos de uma mesma cova diferem quanto ao tamanho, pois a sua diferenciação nos estolões ocorre em uma escala de tempo, o que pode afetar a idade fisiológica. Tubérculos pequenos e imaturos apresentam maior período de dormência do que tubérculos grandes e com idade fisiológica avançada (BEUKEMA \& VAN DEER ZAAG, 1990; ITTERSUM et al., 1993; PÓGI \& BRINHOLI, 1995). A extensão de como a idade fisiológica dos tubérculos afeta o armazenamento depende da cultivar (DRISKILL Jr. et al., 2007), mas as épocas de cultivo de primavera e outono podem superar as diferenças genéticas. Tubérculos produzidos durante o cultivo de primavera atingem similar idade fisiológica na metade do tempo de armazenamento a $12^{\circ} \mathrm{C}$, diferente daqueles produzidos durante o outono (BISOGNIN et al., 2008), ou seja, as condições de cultivo de outono prolongam a dormência dos tubérculos. A dormência também deve ser considerada quando os tubérculos são utilizados como semente. Tubérculos grandes apresentam uma rápida emergência de um grande número de hastes e hastes mais altas do que tubérculos pequenos, o que requer o plantio em separado e em diferentes densidades (BISOGNIN et al., 1998).

Portanto, qualquer fator que favoreça os promotores em detrimento dos inibidores do crescimento aumenta a atividade metabólica dos tubérculos e diminui o período de dormência, mesmo durante o armazenamento. Além disso, o tamanho dos tubérculos deve ser considerado tanto para o seu próprio armazenamento quanto para o plantio da batatasemente. A disponibilidade de clones, com diferentes períodos de dormência e de dominância apical, de época de cultivo que maximiza a dormência e de condições controladas de armazenamento, possibilita avaliar conjuntamente os possíveis efeitos sobre a idade fisiológica dos tubérculos de batata de diferentes tamanhos e oriundos de uma mesma cova.

O objetivo deste trabalho foi avaliar o período de dormência e de dominância apical de diferentes tamanhos de tubérculos de três clones de batata, produzidos no outono e submetidos a duas temperaturas de armazenamento.

\section{MATERIAL E MÉTODOS}

Os tubérculos de dois clones avançados (SMIJ461-1 e SMINIA00017-6) do Programa de Genética e Melhoramento de Batata da Universidade Federal de Santa Maria (UFSM) e a cultivar Asterix, amplamente cultivada na região central do Rio Grande do Sul (RS), foram produzidos no campo experimental do Departamento de Fitotecnia da UFSM, RS, durante o cultivo de outono de 2008. Para simplificação, a cultivar Asterix também será referida como clone. A escolha dos clones se deveu às diferenças da duração do período de dormência, o que é desejável para aumentar a inferência dos resultados. Os tratos culturais, o manejo das plantas e a dessecação da parte aérea com Paraquat, 10 dias antes da colheita, seguiram as recomendações técnicas para o cultivo da batata (BISOGNIN, 1996). Foram colhidos separadamente todos os tubérculos dos três clones produzidos em dez covas. Após a cura (armazenamento a $20^{\circ} \mathrm{C}$ por 15 dias para a suberização da periderme), os tubérculos de cada cova foram individualmente identificados e 
avaliados para massa fresca, comprimento e maior e menor diâmetros. Os tubérculos de cada clone foram divididos em dois lotes de cinco covas e armazenados nas temperaturas de 10 e $20^{\circ} \mathrm{C} \pm 2^{\circ} \mathrm{C}$, para diferenciar a duração do período de dormência, em julho de 2008. A umidade relativa do ar no interior das câmaras foi mantida em $85 \% \pm 5 \%$.

Semanalmente, foi contado o número de brotos por tubérculo até dezembro de 2008. O rompimento da dormência e da dominância apical foi anotado quando o tubérculo apresentou, respectivamente, um ou dois brotos. Foi considerado broto quando este apresentava $2 \mathrm{~mm}$ de comprimento (COLEMAN, 1998). Os dados dos tubérculos que não apresentaram rompimento da dormência ou da dominância apical durante o período de 170 dias de armazenamento não foram utilizados para a análise.

$\mathrm{O}$ experimento foi conduzido em um fatorial de três clones (SMINIA00017-6, SMIJ461-1 e Asterix), duas temperaturas de armazenamento $\left(10\right.$ e $\left.20^{\circ} \mathrm{C}\right)$ e três tipos de tubérculo (menor diâmetro inferior a $35 \mathrm{~mm}$, entre 35 e $45 \mathrm{~mm}$ e superior a $45 \mathrm{~mm}$ ), no delineamento experimental inteiramente casualizado, com cinco repetições de uma cova. Os dados foram submetidos à análise da variância e as médias comparadas pelo teste Tukey. Os dados de número de dias até o rompimento da dormência e da dominância apical dos tubérculos foram submetidos à análise de correlação de Pearson com o comprimento, menor e maior diâmetros e massa fresca. As análises foram realizadas com o auxílio do programa NTIA (EMBRAPA, 1997) e significância de $5 \%$ de probabilidade de erro.

\section{RESULTADOS E DISCUSSÃO}

Os tamanhos de tubérculo separados pelo menor diâmetro em inferior a $35 \mathrm{~mm}$, entre 35 e $45 \mathrm{~mm}$, e superior a $45 \mathrm{~mm}$ resultou em uma quantidade equilibrada de tubérculos dos diferentes clones que romperam tanto a dormência quanto a dominância apical até os 170 dias de armazenamento (Tabela 1). As diferenças de massa fresca média encontradas entre tipos e clones eram esperadas, uma vez que essas diferenças são consequência dos diferentes formatos de tubérculo. O clone SMIJ461-1 apresenta tubérculos arredondados e os demais são alongados.

A análise da variância não mostrou diferenças significativas $(\mathrm{P}<0,05)$ para as interações entre clones, temperaturas de armazenamento e tipos de tubérculo (Tabela 2). Entretanto, houve diferenças significativas entre clones, temperaturas de armazenamento e tipos de tubérculo. Asterix apresentou o maior número de dias necessários, tanto para o
Tabela 1 - Massa fresca média e número e percentagem de tubérculos que apresentaram rompimento da dormência e da dominância apical para cada tipo de tubérculo de três clones de batata produzidos no outono e armazenados durante 170 dias a 10 e $20^{\circ} \mathrm{C}$.

\begin{tabular}{|c|c|c|c|c|}
\hline $\begin{array}{l}\text { Clones de } \\
\text { batata }\end{array}$ & $\begin{array}{l}\text { Tipo de } \\
\text { tubérculo* }\end{array}$ & $\begin{array}{c}\text { Massa } \\
\text { fresca } \\
\text { média }(\mathrm{g})\end{array}$ & $\begin{array}{l}\text { Número de } \\
\text { tubérculos }\end{array}$ & $\begin{array}{c}\% \text { de } \\
\text { tubérculos }\end{array}$ \\
\hline & \multicolumn{4}{|c|}{------------- Rompimento da dormência ------------ } \\
\hline \multirow{4}{*}{ Asterix } & $<35$ & 15,01 & 27 & 54,0 \\
\hline & $35-45$ & 36,91 & 10 & 20,0 \\
\hline & $>45$ & 86,46 & 13 & 26,0 \\
\hline & $<35$ & 12,82 & 21 & 37,5 \\
\hline \multirow[t]{3}{*}{ SMIJ461-1 } & $35-45$ & 32,32 & 18 & 32,1 \\
\hline & $>45$ & 80,95 & 17 & 30,4 \\
\hline & $<35$ & 14,52 & 33 & 35,9 \\
\hline \multirow[t]{4}{*}{ SMINIA00017-6 } & $35-45$ & 42,82 & 31 & 33,7 \\
\hline & $>45$ & 73,44 & 28 & 30,4 \\
\hline & \multicolumn{4}{|c|}{-------- Rompimento da dominância apical ------ } \\
\hline & $<35$ & 19,03 & 11 & 37,9 \\
\hline \multirow[t]{3}{*}{ Asterix } & $35-45$ & 40,66 & 7 & 24,2 \\
\hline & $>45$ & 87,60 & 11 & 37,9 \\
\hline & $<35$ & 16,86 & 6 & 20,7 \\
\hline \multirow[t]{3}{*}{ SMIJ461-1 } & $35-45$ & 34,36 & 8 & 27,6 \\
\hline & $>45$ & 83,85 & 15 & 51,7 \\
\hline & $<35$ & 16,00 & 9 & 20,5 \\
\hline \multirow[t]{2}{*}{ SMINIA00017-6 } & $35-45$ & 47,67 & 17 & 38,6 \\
\hline & $>45$ & 77,52 & 18 & 40,9 \\
\hline
\end{tabular}

* Classificados conforme o menor diâmetro medido em mm.

rompimento da dormência quanto da dominância apical. O período de dormência do clone SMINIA00017-6 foi 29\% menor do que da Asterix. As diferenças entre clones confirmam que o período necessário para o

Tabela 2 - Número de dias até o rompimento da dormência e da dominância apical de tubérculos de três clones de batata produzidos no outono, separados por tipo e armazenados a 10 e $20^{\circ} \mathrm{C}$

\begin{tabular}{lcc}
\hline & Dias de armazenamento para o rompimento \\
Tratamentos & Dormência & Dominância apical \\
\hline Clones & & \\
Asterix & $136,75 \mathrm{~A} \mathrm{a}$ & $145,76 \mathrm{~A} \mathrm{a}$ \\
SMIJ461-1 & $109,14 \mathrm{~A} \mathrm{~b}$ & $122,76 \mathrm{~A} \mathrm{~b}$ \\
SMINIA00017-6 & $97,12 \mathrm{~B} \mathrm{c}$ & $113,02 \mathrm{~A} \mathrm{~b}$ \\
Temperatura & & \\
$10^{\circ} \mathrm{C}$ & $132,42 \mathrm{~A} \mathrm{a}$ & $134,67 \mathrm{~A} \mathrm{a}$ \\
$20^{\circ} \mathrm{C}$ & $96,73 \mathrm{~B} \mathrm{~b}$ & $120,16 \mathrm{~A} \mathrm{~b}$ \\
Tipo de tubérculo & & \\
$<35 \mathrm{~mm}$ & $118,33 \mathrm{~B} \mathrm{a}$ & $133,54 \mathrm{~A} \mathrm{a}$ \\
$35-45 \mathrm{~mm}$ & $111,24 \mathrm{~A} \mathrm{~b}$ & $125,34 \mathrm{~A} \mathrm{a} \mathrm{b}$ \\
$>45 \mathrm{~mm}$ & $108,70 \mathrm{~A} \mathrm{~b}$ & $122,38 \mathrm{~A} \mathrm{~b}$ \\
$\mathrm{CV}(\%)$ & 7,81 & 10,63 \\
\hline
\end{tabular}

Médias não seguidas pela mesma letra, minúscula na coluna e maiúscula na linha, diferem estatisticamente entre si pelo teste de Tukey, em nível de 5\% de probabilidade de erro. 
rompimento da dormência e da dominância apical, bem como o período entre o rompimento da dormência e da dominância apical são caracteres genéticos. O clone SMINIA00017-6 foi o único que diferiu quanto à duração do período de dominância apical, ou seja, o período entre o rompimento da dormência e da dominância apical. A dominância apical é indesejável para a batata-semente, pois o plantio nesse estágio resulta em uma lavoura com poucas hastes e baixo potencial produtivo (HIRANO, 2003; BISOGNIN et al., 2008).

Tubérculos armazenados a $10^{\circ} \mathrm{C}$ apresentaram maior período de dormência e de dominância apical do que aqueles armazenados a $20^{\circ} \mathrm{C}$ (Tabela 2). Entretanto, a temperatura de armazenamento de $10^{\circ} \mathrm{C}$ promoveu o rompimento da dominância apical praticamente junto com a dormência, ou seja, assim que rompeu a dormência ocorreu a brotação múltipla dos tubérculos, caracterizando o estágio de plena brotação. Portanto, a temperatura de $20^{\circ} \mathrm{C}$ adiantou e a $10^{\circ} \mathrm{C}$ atrasou a brotação dos tubérculos, confirmando o efeito da elevação da temperatura de $10^{\circ} \mathrm{C}$ para $20^{\circ} \mathrm{C}$ no rompimento da dormência (BEUKEMA\& VAN DER ZAAG, 1990). Além disso, a temperatura de $20^{\circ} \mathrm{C}$ foi mais eficaz em romper a dormência. A aspersão dos tubérculos com ácido giberélico também adianta a brotação. A aplicação de $30 \mathrm{mg} \mathrm{L}^{-1}$ de ácido giberélico reduz o período até a emergência das hastes em $25 \% \mathrm{e}$ aumenta tanto o número de hastes por $\mathrm{m}^{2} \mathrm{em} 37,8 \%$ quanto o rendimento total em 13,8\% em relação ao controle (BISOGNIN et al., 1998). Entretanto, a eficácia do tratamento depende do nível de dormência dos tubérculos, pois minitubérculos do clone SMIJ461-1 produzidos no outono não romperam a dormência até os 60 dias de armazenamento a $20^{\circ} \mathrm{C}$, sendo que aqueles da cultivar 'Macaca' romperam a dormência e a dominância apical (BENEDETTI et al., 2005).

Tubérculos pequenos apresentaram maior período de dormência e de dominância apical do que tubérculos grandes (Tabela 2). Além disso, tubérculos com menor diâmetro, inferiores a $35 \mathrm{~mm}$, diferiram quanto à duração do período de dominância apical. Esses resultados mostram que há uma relação entre o tamanho e a idade fisiológica dos tubérculos em uma mesma cova, ou seja, tubérculos maiores têm idade fisiológica mais avançada do que os menores e, em consequência, menor período de dormência. Além disso, tubérculos com menor diâmetro, superior a $35 \mathrm{~mm}$, já apresentaram idade fisiológica avançada, pois não diferiram daqueles com menor diâmetro, superior a $45 \mathrm{~mm}$, quanto ao número de dias necessários para o rompimento da dormência e da dominância apical. Portanto, os tubérculos podem ser separados pelo menor diâmetro em maiores e menores do que $35 \mathrm{~mm}$. Entretanto, para o plantio, os tubérculos-semente devem ser classificados em um maior número de tipos com a finalidade de uniformizar a densidade de hastes e a altura das plantas, facilitar o manejo e os tratos culturais bem como maximizar o rendimento (BISOGNIN et al., 1998).

O tamanho do tubérculo, caracterizado pela massa fresca, pelo comprimento e pelo maior e menor diâmetros, apresentou um maior número de correlação linear significativa com o número de dias necessários para o rompimento da dormência, diferente da dominância apical (Tabela 3). Em geral, a análise de correlação mostrou que quanto maior a massa fresca do tubérculo menor foi o período de dormência. Correlações lineares não significativas somente foram obtidas para os tubérculos dos clones Asterix, armazenados a $10^{\circ} \mathrm{C}$ e SMINIA00017-6, armazenados a $20^{\circ} \mathrm{C}$. Esses resultados podem estar associados ao fato de que o clone Asterix apresentou o maior e o clone SMINIA00017-6 o menor período de dormência e que o armazenamento a $10^{\circ} \mathrm{C}$ retardou a brotação dos tubérculos (Tabela 1). Correlações significativas entre o tamanho do tubérculo e o número de dias necessários para o rompimento da dominância apical somente foram obtidos para os clones SMIJ461-1 e SMINIA00017-6, armazenados $10^{\circ} \mathrm{C}$. Esses resultados podem estar associados ao maior período de dominância apical dos tubérculos armazenados a $20^{\circ} \mathrm{C}$ do que a $10^{\circ} \mathrm{C}$ (Tabela 1), ou seja, as diferenças de idade fisiológica foram mascaradas pelo armazenamento a $20^{\circ} \mathrm{C}$, cuja temperatura foi pouco eficaz em romper a dominância apical dos tubérculos.

O rompimento da dormência e da dominância apical são dois eventos fisiológicos importantes, tanto para os tubérculos destinados ao consumo quanto para semente. A manutenção da dormência é fundamental para a qualidade dos tubérculos, pois o início da brotação desencadeia um processo contínuo de aumento da percentagem de tubérculos brotados e do número de brotos por tubérculo, que resultam em um aumento da respiração e das perdas de massa fresca (BISOGNIN et al., 2008). Portanto, a brotação dos tubérculos promove perdas qualitativas e quantitativas, devido ao aumento da atividade metabólica. Considerando que nas principais regiões produtoras do Rio Grande do Sul a batata pode ser cultivada em duas safras anuais, o rompimento da dormência e da dominância apical é necessário para as cultivares cujos períodos são maiores do que o de entre safras (BISOGNIN, 1996; BISOGNIN et al., 2008). O desenvolvimento de novas cultivares de curta dormência pode reduzir muito o tempo disponível para 
Tabela 3 - Correlação entre as variáveis de tamanho de tubérculos e número de dias necessários até o rompimento da dormência e da dominância apical de três clones de batata produzidos no outono e armazenados a $10^{\circ} \mathrm{C}$ e $20^{\circ} \mathrm{C}$.

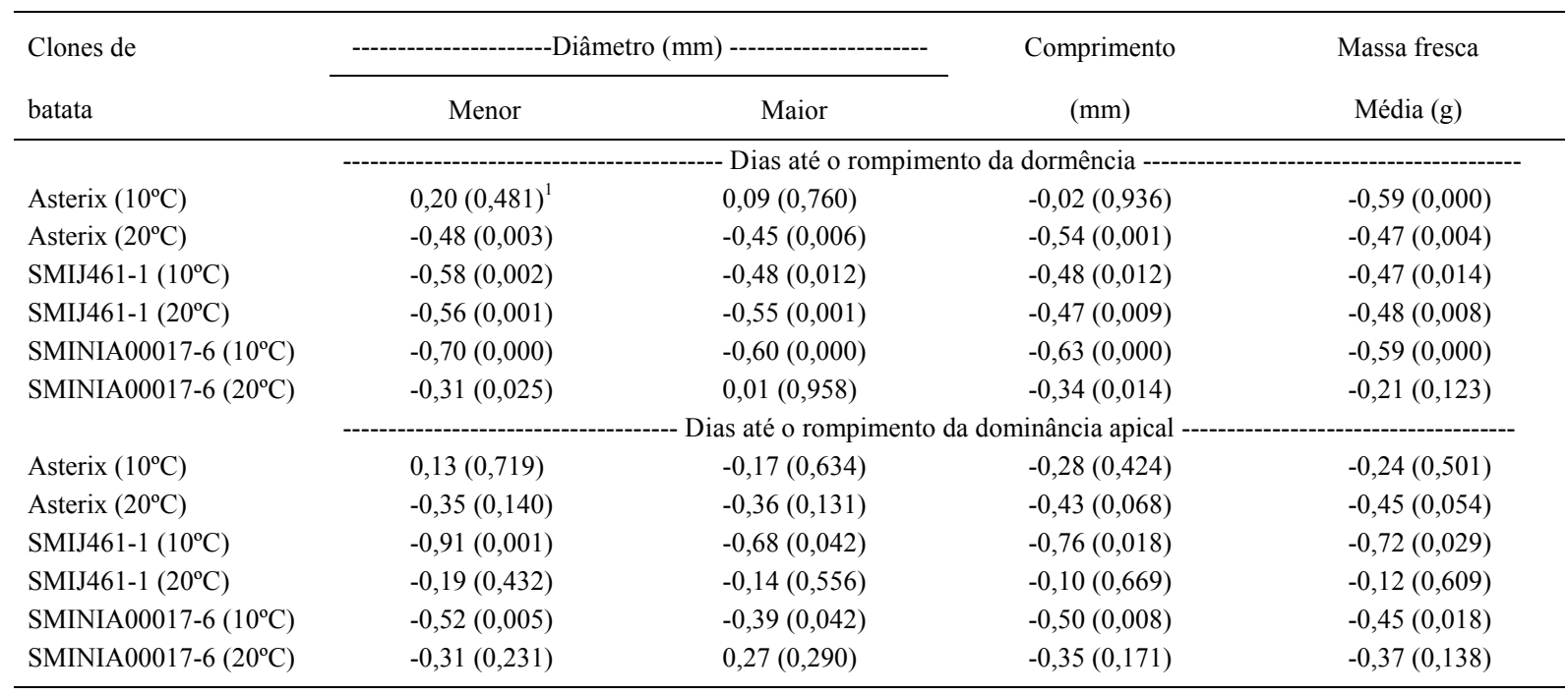

${ }^{1}$ Probabilidade para determinar a significância da correlação.

a comercialização ou a utilização dos tubérculos, pois a brotação aumenta as perdas de massa fresca e deprecia o produto para o comércio in natura, além de o acúmulo de açúcares redutores inviabilizar o processamento industrial, o que invariavelmente reduz o retorno econômico (BEUKEMA \& VAN DER ZAAG, 1990). O crescimento e a ramificação contínua dos brotos promovem o esgotamento das reservas dos tubérculos, que seriam necessárias para a adequada emergência das hastes, quando utilizados como batata-semente. Esse processo de perdas qualitativas e quantitativas desencadeado pela brotação dos tubérculos independe da cultivar e das condições de cultivo, já que a temperatura de armazenamento exerce pouca influência sobre este procedimento (BISOGNIN et al., 2008).

Os resultados deste trabalho estão de acordo com a literatura de que a dormência e a dominância apical dos tubérculos de batata são caracteres genéticos e que a elevação da temperatura de armazenamento promove o rompimento da dormência e da dominância apical (BEUKEMA \& VAN DER ZAAG, 1990 ), mesmo de $10^{\circ} \mathrm{C}$ para $20^{\circ} \mathrm{C}$. Considerando os diferentes tamanhos de tubérculos e clones avaliados neste trabalho, a temperatura de armazenamento de $20^{\circ} \mathrm{C}$ foi mais eficaz para o rompimento da dormência do que da dominância apical. Como a redução da temperatura de armazenamento aumentou o período de dormência e reduziu as perdas de massa fresca dos tubérculos (BISOGNIN et al., 2008) e a temperatura de $10^{\circ} \mathrm{C}$ foi mais eficaz em romper a dominância apical, o armazenamento da batata-semente deve ser feito em temperaturas mais baixas, desde que haja disponibilidade de tempo até o próximo plantio. Também, a idade fisiológica está associada ao tamanho dos tubérculos, podendo ser considerado o menor diâmetro de $35 \mathrm{~mm}$ para separar o comportamento fisiológico dos tubérculos, medido pelo período de dormência e de dominância apical. Tanto o menor diâmetro, que é usado para classificar comercialmente a batata, quanto os demais parâmetros utilizados para caracterizar o tamanho de tubérculo estiveram inversamente correlacionados com o número de dias até o rompimento da dormência. No entanto, as variações de tamanho e idade fisiológica dos tubérculos podem ser superadas com o adequado manejo póscolheita, desde que respeitadas as diferenças de idade fisiológica associadas ao menor diâmetro, superior ou inferior a $35 \mathrm{~mm}$. Portanto, parâmetros como a idade fisiológica, o tempo disponível para o armazenamento e a finalidade de uso dos tubérculos devem ser considerados para definir a temperatura ideal de armazenamento.

\section{CONCLUSÃO}

A partir dos resultados, conclui-se que a idade fisiológica varia com o tamanho dos tubérculos de batata, sendo que tubérculos com menor diâmetro, inferiores a $35 \mathrm{~mm}$, apresentam maior período de dormência. Além disso, a temperatura de 
armazenamento de $20^{\circ} \mathrm{C}$ é mais eficaz para o rompimento da dormência do que da dominância apical.

\section{AGRADECIMENTOS}

Ao Conselho Nacional de Desenvolvimento Científico e Tecnológico (CNPq), pelo financiamento parcial e pela concessão de bolsas de pesquisa e iniciação científica, e à Fundação de Amparo à Pesquisa do Estado do Rio Grande do Sul (FAPERGS), pela concessão de bolsa de iniciação científica.

\section{REFERÊNCIAS}

BENEDETTI, M. et al. Quebra de dormência de minitubérculos de batata. Ciência Rural, Santa Maria, v.35, n.1, p.31-38, 2005. Disponível em: <http://www.scielo.br/scielo.php?pid=S0103$84782005000100006 \&$ script $=$ sci arttext $>$. Acesso em: 08 out. 2009. doi: $10.1590 / \mathrm{S} 0103-84782005000100006$.

BEUKEMA, H.P.; VAN DER ZAAG, D.E. Introduction to potato production. Wageningen: PUDOC, 1990. 208p.

BISOGNIN, D.A. Recomendações técnicas para o cultivo da batata no Rio Grande do Sul e Santa Catarina. Santa Maria: Universidade Federal de Santa Maria, 1996. 64p.

BISOGNIN, D.A. et al. Uso do ácido giberélico na quebra de dormência e de dominância apical em batata. Ciência Rural, Santa Maria, v.28, n.2, p.205-213, 1998. Disponível em: <http:/ /www.scielo.br/scielo.php?script $=$ sci arttext\&pid $=\mathrm{S} 0103$ 84781998000200004>. Acesso em: 08 out. 2009. doi: 10.1590/ S0103-84781998000200004.

BISOGNIN, D.A. et al. Envelhecimento fisiológico de tubérculos de batata produzidos durante o outono e a primavera e armazenados em diferentes temperaturas. Bragantia, Campinas, v.67, n.1, p.59-65, 2008. Disponível em: <http:// www.scielo.br/scielo.php?script $=$ sci_arttext\&pid $=$ S0006$87052008000100007 \& \operatorname{lng}=\mathrm{pt} \& \mathrm{nrm}=\mathrm{iso}>$. Acesso em: 12 out. 2009. doi: 10.1590/S0006-87052008000100007.

CALDIZ, D.O. et al. Physiological age index: a new, simple and reliable index to assess the physiological age of seed potato tubers based on haulm killing date and length of the incubation period. Field Crops Research, Amsterdam, v.69, n. 1, p.6979, 2001. Disponível em: <http://www.sciencedirect.com/ science?_ob=MImg\&_imagekey=B6T6M-41 TN40H-6$\mathrm{F} \&$ _cdi $=5034 \&$ _user $=687358 \&$ pii $=\mathrm{S} 0378429000001349 \&$ _orig $=$ search\&_coverDate $=01 \% 2 \mathrm{~F} 31 \% 2 \mathrm{~F} 2001 \&$ \&s $=9993099$ 98\&view $=\mathrm{c} \& w c h p=d G L b V l b z S k z S \& m d 5=7 c 179 c 2021 b 7 e 80793088$ fd153b82c56\&ie=/sdarticle.pdf $>$. Acesso em: 12 out. 2009. doi: $10.1016 / \mathrm{S} 0378-4290(00) 00134-9$.

COLEMAN, W.K. Carbon dioxide, oxygen and ethylene effects on potato tuber dormancy release and sprout growth. Annals of Botany, Oxford, v.82, p.21-27, 1998. Disponível em: <http:/ / a ob.oxfordjournals.org/cgi/reprint/82/1/ 21 ? maxtoshow $=\&$ hits $=10 \&$ RESULTFORMAT $=1 \&$ title $=$ Carbon + dioxide $\% 2 \mathrm{C}+$ oxygen + and + ethylene + effects + on + potato + tuber $+\mathrm{d}$ ormancy + release + and \&andorexacttitle $=$ and \&andorexacttitleabs $=$ and \&andorexactfulltext $=$ and \&searchid $=1 \&$ FIRSTINDEX $=0 \&$ sortsp $\mathrm{ec}=$ relevance $\&$ resourcetype $=$ HWCIT $>$. Acesso em: 12 nov. 2009.

DRISKILL Jr., E.P. et al. Temperature-induced changes in potato processing quality during storage are modulated by tuber maturity. American Journal of Potato Research, Maine, v.84, n.5, p.367-383, 2007. Disponível em: <http:// www.springerlink.com/content/363g59465775h34n/ fulltext.pdf>. Acesso em: 11 nov. 2009. doi:10.1007/ BF02987183.

EMBRAPA. Ambiente de software NTIA: manual do usuário. Campinas: Embrapa-CNPTIA, 1997. 258p. (versã0 4.2.2).

FONTES, P.C.R.; FINGER, F.L. Dormência dos tubérculos, crescimento da parte aérea e tuberização da batateira. Informe Agropecuário, Belo Horizonte, v.20, n.197, p.24-29, 1999.

FONTES, P.C.R.; FINGER, F.L. Pós-colheita do tubérculo de batata. Viçosa: UFV, 2000. 32p.

HIRANO, E. Colheita e pós-colheita de batata-semente. In: PEREIRA, S.A.; DANIELS, J. O cultivo da batata na Região Sul do Brasil. Brasília: Embrapa, 2003. p.509-528.

ITTERSUM, M.K.V. et al. Advancing growth vigor of seed potatoes by a halum application of gibberellic acid and storage temperature regimes. American Potato Journal, Maine, v.70, n.1, p.21-34, 1993.

PÓGI, M.C.; BRINHOLI, O. Efeitos da maturidade, do peso da batata-semente e da quebra da dormência sobre a cultivar de batata (Solanum tuberosum L.) Itararé (IAC 5986). Pesquisa Agropecuária Brasileira, Brasília, v.30, n.11, p.1305-1311, 1995. Disponível em: <http://webnotes.sct.embrapa.br/pab/ pab.nsf/4b9327fca $7 \mathrm{faccde} 032564 \mathrm{ce} 004 \mathrm{f} 7 \mathrm{a} 6 \mathrm{a} /$ $6 \mathrm{f} 68303 \mathrm{~d} 1 \mathrm{c} 7 \mathrm{f} 06 \mathrm{ba} 032567 \mathrm{db} 004 \mathrm{ca} 832 /$ FILE/ pab95_04_nov.pdf>. Acesso em: 01 nov. 2009. 